\title{
18 Insights Gained on the Great Recession's Effects
}

\author{
fohn Bynner, Glen H. Elder Fr.,Walter R. Heinz, \\ Ingrid Schoon
}

\section{What Have We Learned?}

What have we learned about the changing nature of youth transitions and the effect of the Great Recession on them? In this final chapter we draw conclusions and seek further insights from the evidence presented. First we give a brief overview, taking the discussion back to the initial questions about the recession effects to which the preceding chapters were directed. Second, we discuss the evidence in the light of key themes of contemporary youth research and draw out their intersection with life course theory. We then consider the theoretical and policy insights to be gained from the evidence reported. Our discussion focuses on young people in the USA, the UK, and Germany, but also takes into account developments across a range of industrialized countries.

\section{Overview}

What was the impact of the Great Recession on young people making the transition to independent adulthood? The overall conclusion to be drawn is that the Great Recession was a significant but not principal influence on young people's changing life course post-2007. Better to characterize it as a major economic shock that intensified the impact of preexisting economic and social processes on young people's lives. Originating principally in Western countries in the period of technological transformation and de-industrialization of the late 1970s, as the contributors to the book show, these effects presented new obstacles to entering and sustaining employment within the adult labor market. There were also wider repercussions for functioning in the family and other life domains. Although the short-term effects may have been modest, they might be followed by more serious outcomes and long-term scarring effects. There could also be lagged effects (i.e., a delay between the exposure and onset of adjustment problems) and therefore continued monitoring of life chances for young people is necessary. 
The recession effects varied with each successive cohort embarking on the transition to independent adulthood, i.e., they differed for different age groups, for different countries, and between different sections of the youth population. Younger cohorts, aged 15-18 when the effects of the Great Recession began to be felt, faced heightened difficulties in gaining entry to jobs or to the vocational education and training (VET) routes that previously ensured access to them. The consequence was extended dependence on the family to support the young people staying on in education to gain the certification that employers were increasingly demanding. At the same time, for those on the route to professional occupations via higher education, increasing competition, and in some countries charging for the first time or raising existing tuition fees, added to the pressures on young people and their parents. For the older cohort aged 19-25, the problems encountered were of a contracting labor market, downsizing of firms, and employment contracts lacking job security. With the exception of Germany, there was also rising unemployment and even university graduates were increasingly encountering problems in finding employment matching their qualifications and skills.

We consider the implications of such change for the forms and extent of social stratification and inequality later. But a significant feature to be identified now is what is increasingly described in industrialized countries as a "precariat". That is to say there are signs of a growing section of the population encountering low paid temporary jobs and unemployment for whom difficulties in making key transitions lays the foundations for exclusion from prospects in the mainstream economy. Such a trend, though longstanding, was intensified by the Great Recession placing particular pressures on families.

Postponed commitments in the form of partnership and parenthood were another prominent feature of the changing context. Moreover, the experience of hardship undermined feelings of closeness, producing conflict with parents. The role of fathers was particularly affected, with unemployment impacting negatively on their children's progress and relationships with them, especially among boys - aligning with Glen Elder's comparable findings on the impact on young people of the 1930s Great Depression. As in the Great Depression, relationships between parents and their children were affected and the development of selfefficacy, achievement motivation, and other forms of self-regulation emerged as significantly diminished, as was trust in government institutions and civic engagement. There was disillusion with government performance among young people in countries with the highest levels of youth unemployment - though this negative appraisal did not extend 
generally to the rejection of democracy itself, except among the youngest respondents.

Youth transitions have much significance in the foundation of adult identity. This significant period - constituting a "rite of passage" - supplies the means of achieving the capability needed for effective functioning in all the domains of adult life that follow. In the immediate term, the achieved transition status gives signals of employability. Failure to pass through the transition successfully can then leave the young person lacking confidence and self-esteem and in the eyes of employers, permanently "scarred". Yet at the same time, young people's experience in what were the dire economic circumstances of some countries in southern Europe, such as Greece or Spain, also pointed to the forging of positive relationships with the future, pointing to manifestations of resilience. That is to say, adversity was countered for many young people by optimism that opportunities were present, or would emerge for a fulfilling life achieved in other ways besides that of the traditional occupational career, or by moving to another country offering better prospects.

Other effects of the Great Recession depended on the timing of events (i.e., when they occurred in young people's lives), and on the outcome. For example, the psychological well-being of adolescents (aged 11-15 years) appeared to be relatively unaffected by the Great Recession while the older cohort (18-25) was more vulnerable to its psychological effects. Physical health and health-related behaviors like smoking and drinking across all age groups appeared largely unaffected.

\section{Policy Response}

Of particular significance was the policy response to these effects, highlighting the crucial role of institutional leverage in different countries protecting young people from the effects of the global financial meltdown. The different education, training, employment, and welfare systems in different countries had a significant role, in mediating and moderating the Great Recession's effects. Such cross-national variation is manifested in the Vocational Education and Training (VET) system (school or employment based), or lack of it, through which the nonacademic pathway is managed. The strongly occupation based "dual system" of Germany contrasts with the exclusively school-based system of high school graduation in the USA and the "mixed system" of schooling, college, employment, apprenticeship, and government-supported training operating in the UK.

As will be further discussed in this chapter, Germany led the way in the support given to most young people for making a successful transition 
from education to the labor market regardless of hostile economic circumstances. The price to pay was a transformed labor market in which insecure "non-standard" employment was becoming a major feature. In contrast, in the UK and the USA the arrangements for managing youth transitions at times of economic stress appeared to be patchy and less coherent. The critical factor in accessing employment after the recession was the buoyancy of national and local labor markets.

\section{Life Course Perspective Revisited}

Taken together the findings inform the conceptualization of youth transitions within a social ecology framework guided by life course theory. That is to say, referring back to Chapter 1, we use theory that encompasses the structural forces and processes of individual and collective adaptation operating in times of massive labor market transformation. The contribution of the research reported was to identify the effects of the financial crisis versus preexisting trends of accelerated youth transitions.

Part II of the book addresses the structural changes embodied in the socioeconomic trends that preceded the banking collapse and the recession that followed. The historical overview provided by Ashton in Chapter 2 highlights a number of features of the changing life course occurring since the 1970s that supply useful guidance for interpreting the findings on the Great Recession's effects - including variations across subgroups within and between countries. He argues that the main effect of the Great Recession was to speed up existing trends toward "deskilling" and casualization of the labor force to which young people were particularly vulnerable. Government interventions then became the main means of moderating the labor market effects, including the differences between Germany, the USA, and the UK in this respect. Mont'Alvao, Mortimer and Kirkpatrick Johnson (Chapter 3) add to the picture, by examining the effects of changing (adult) labor market conditions on youth unemployment, underemployment, and family stress, post-2007, coupled with the decline in public services that had previously helped to mitigate them. Effects on the pathways between schooling and employment are also considered together with the supply and demand for higher education. They show that these structural forces prompted new relations between the individual and the labor market as reflected in the changing life course.

Green and Pensiero (Chapter 4) move the focus to post-compulsory education and training. They review the differences in VET transition systems and associated adult basic skills outcomes between countries grouped broadly in terms of political economy. They link these country 
differences to changing participation rates since the 2008 banking collapse in further and higher education, youth and graduate unemployment and employment rates, graduate wage premia, and rates of return to university degrees. Only modest effects are identified, leading them to conclude that changing local labor market conditions are the critical factor in mediating economic change. They also argue for active labor market policy intervention to protect young people's transitions.

Such elements of the contemporary context overlap with, but are in certain respects quite distinct from, those prevailing for young people at the time of the 1930s Great Depression. The common ground is the core life course principles of agency, linked lives, timing of experience, and location in (historical) time and space. The changing sociohistorical context includes new structural forces impacting on and contributing to variations in individual life courses, as reflected in the processes of (de)standardization, individualization (coupled with globalization), stratification, and precaritization, which we now consider. We move next to the key developmental micro-processes, i.e., the marshaling of personal and family resources, which follow from these principles, summed up as adaptation to changing circumstances. The implications for political engagement and civic values follow, then health.

\section{De-Standardization}

De-standardization refers to the timing and the sequencing in which youth transitions tend to occur (Buchmann and Kriesi 2011; Shanahan 2000). Since the 1970s, in response to the changing labor market, there has been a continuing extension of the period of full-time education. The transition to independent adulthood has been prolonged especially with regard to entry into employment, stable partnership, and parenthood. Furthermore, configurations of young adult statuses lacking full financial autonomy and independence challenge the very basis of adult identity as traditionally understood "citizenship by proxy" as Jones and Wallace (1992) described it. In this sense, transitions have become "de-standardized", referring to the progression of individuals through prescribed phases of life and the timing and sequencing of transitions into social roles. As Crosnoe and Smith (Chapter 6), and Lyons-Amos and Schoon (Chapter 12) show, configurations of young adult statuses changed across cohorts following the Great Recession, leading to a "decoupling" of transitions such as family formation, e.g., marriage and parenthood, from labor market entry.

Overall, the findings suggest that the impact of the Great Recession on the timing and sequencing of youth transitions was less transformative 
in the direction of de-standardization than reinforcing preexisting trends toward extended and more complex transitions. The origins of concurrent trends lay, as Ashton shows in Chapter 2, in the technological transformation of industry and globalization and their implications for the nature of work and the occupational structure. There was a dramatic growth of white collar, high tech, and service jobs at the expense of manufacturing and unskilled work accompanied by "deskilling" of many of those employed in what had been skilled occupations. The counterpart was a growing demand from employers for educational credentials and the increasing exclusion from mainstream employment for those without them. In consequence there was an incentive to prolong the participation in full-time education in order to obtain further and advanced qualifications through college and university studies, especially among young women who became more likely than young men to continue on the academic pathway to higher education. This trend was accompanied by a general tendency to postpone the kinds of commitment that marriage and parenthood demand.

The positive side of this development is a kind of "moratorium" on adult obligations and responsibilities (in "Eriksonian" terms) in favor of identity exploration (Côté and Levine 2002). One consequence was the idea of a new psychosocial developmental stage of "emerging adulthood" proposed by Jeffrey Arnett (2000). Such a status, applying to a sizable proportion of the age cohort, tends, however, to deny the heterogeneity of young people's experience (Bynner 2005; Côté and Bynner 2008; Schoon and Lyons-Amos 2016, 2017). While increasing numbers of young people participate in higher education, many are doing so by working their way through college, and others continue to move into the labor market at the earliest possible age, often complementing that experience with early partnership and parenthood.

The assumption of a homogenization of transition experience, resonating with ideas of relatively fixed life course stages, overlaying biological development, was always to a certain extent an idealized model out of step with reality. "Stratification," in terms of occupational destination and accelerated or prolonged transition experiences leading it (which we consider later), challenges the standardization concept. This is more than ever the case today through the further intensification of "individualization," which increasingly characterizes youth transitions, and which we consider next.

\section{Individualization and Globalization}

The phenomenon of individualization, as formulated in Ulrich Beck's (1992) Risk Society, rests on the hypothesis that since the 1970s individual 
behavior has become less bound by traditional norms and values and sources of collective identity such as class, gender, and ethnicity. Instead, Beck argued that life is increasingly perceived as a "reflexive" or selfsteered phenomenon, governed by risks that have to be circumvented; that is to say "something you must largely accomplish yourself." The life course is thus considered more of a "project" that individuals themselves construct - rather than being shaped by social structures and traditional forms of socialization in work places - as both opportunities and support for normative paths decline (Heinz 2002, 2009).

While generally accepting Beck's argument, others have stressed the persistence of structural pressures restricting the opportunities to succeed and presenting obstacles to life course construction that contemporary young people face. Such "structured individualization," stressing the interaction between individual agency and social structure as a basis for understanding young people's situation, is in large part a product of economic transformation (Furlong and Cartmel 1997; Roberts, Clark, and Wallace 1994; Schoon and Lyons-Amos 2017; Shanahan 2000). For example, young women's destinations in the labor market may reflect both individual choices (agency) and discrimination against women in the nature of the transitions they make and the jobs they are able to get (structure), with significant shifts between cohorts (Schoon and Eccles 2014). In other words, individualization is constrained by the persistent variations in social background, age, gender, and migration status.

Allied to the pressures toward individualization, one of its main progenitors was the other major by-product of technological transformation: increasing "globalization". This is the tendency toward global financing and production of the goods, services, and labor markets to support it. Capital movement to maximize profitability and minimize costs is a common feature. International finance knows no boundaries on investment strategies, and consumption patterns, tastes, and markets are replicated globally. "Youth culture" becomes universalized thus providing common ground for communication and engagement. An ever-increasing amount of digital media and access to it, combined with interactivity, contributes to the flow of information to wherever it is needed - as exemplified by Google and Twitter. In addition, social media such as Facebook a vital communication tool for young people, reinforces the lifestyle choices that are made, and may place them in conflict with the older generation.

Furthermore, as documented by Ashton (Chapter 2), multinational and transnational corporations, such as Amazon, Siemens, or the finance industry, have contributed to shaping the opportunity structure through the power they exercise to determine the expansion and shrinking of jobs 
and the kinds of employment contracts on offer. The trend of reducing labor costs has also created a wave of outsourcing (e.g., call centers in India, garment workers in Bangladesh) that reduced the number of entry jobs for young people, at all skill levels.

Globalization has changed the occupational landscapes in most Western societies from a focus on manufacturing and agriculture to service and IT-based industry - a shift to the "knowledge economy" with rising demands on cognitive, social, and skill profiles, precarious employment and increasingly toward a "gig economy" characterized by short-term projects and shift work. As both Iacovou (Chapter 5) and Blossfeld (Chapter 9) document, jobs lost in the manufacturing sector were partly replaced by work in the service industry, with a spread of skill levels, from business management, engineering, and IT in the upper labor market segment to personal and social services, sales, and restaurant services in the lower segment. Whereas the former jobs require a qualification, the latter are entry jobs for school leavers who face low income and uncertain contract conditions - a process that primarily concerns the quality of work for unqualified young women and migrants.

In the USA, as Staff, Ramirez, and Cundiff (Chapter 7) show, most of the traditional spare time teenage jobs had vanished and the number of job starters with fixed-term contracts had increased. This was also the case in the UK and Germany. The contributions by Ashton, Iacovou, Groh-Samberg and Wise, Blossfeld, Mont'Alvao, Mortimer and Kirkpatrick Johnson record this global trend of up- and de-skilling and the replacement of continuing employment by poorly paid short-term and often part-time jobs. This trend was not interrupted by the Great Recession, but rather intensified and stretched out to reduce opportunities for young people at all qualification levels. As a consequence, the gap between the wealthy and the poor has become wider.

The consequences for individualization may be seen in heightened risks in making life course decisions that can lead, at one end of the occupational spectrum to careers at the highest levels of the labor market and at the other, to dead end jobs and cycles of short-term employment gigs and growing disadvantage. Protection against the latter increasingly relies on individual and family resources - an individualized agency response of continually marshalling the available human, social, and psychological capital and processes of "resilience" (Duckworth and Schoon 2012; Mortimer et al. 2014; Schoon 2014) on which future well-being in the contemporary labor market depends. There is however also evidence to suggest, that recognizing the limits in their own capabilities to succeed, young people merge their own 
interests into a common goal, a phenomemon also described in terms of "collective agency" (Schoon and Mortimer, 2017).

\section{Stratification and Precaritization}

Social stratification adds another component to the contextualization of labor market restructuring and individualization, describing structurally driven patterns of inequality within and between different age cohorts and their consequences for life course outcomes (Elder and George 2016). In the broadest sense, stratification refers to any differentiation of a population into groups sharing common characteristics, which may also reflect power, hierarchy, and inequality. Social class, education, gender, locality (including country), ethnicity, religion, and disability are the most obvious stratifiers.

For example, young people from relatively privileged backgrounds and high status socioeconomic backgrounds are more likely to embark on self-directed extended transitions, marked by participation in higher education and delayed entry into employment and family formation. In contrast, less privileged young people are more work-oriented and likely to experience the traditional accelerated transition, characterized by early school leaving, precipitate labor market participation and early family formation. As the contributions by Iacovou, Crosnoe and Smith, Groh-Samberg and Wise, and Blossfeld show, with respect to country differences, there is evidence of relatively protracted youth transitions in Germany and the USA and accelerated transitions in the UK.

Precaritization takes stratification and individualization a stage further, pointing to the emergence of new relationships with the labor market for a growing "marginalized" minority spanning traditional class and education levels. The change is reflected in the growth of temporary poorly paid casual employment, "zero-hour" contracts, and internships. Beset continually by income and other forms of insecurity, such individuals are largely bypassed by the traditional means of achieving solidarity and support through such mechanisms as occupational identity and trade union membership. As Standing (2011) argues, for this group, entry to employment bears no semblance to beginning a career - it is more a means of survival by accepting anything the labor market offers.

A particularly striking feature of this new stratum, based on disengagement offset by transitory, often exploitative employment, is its growing presence in all countries. The apparent success of Germany in staving off, with the help of legislation, unemployment during and after the Great Recession, was bought at the price of job protection for the "insider" section of the workforce (Blossfeld (Chapter 9); Groh-Samberg and 
Wise (Chapter 8)). At the same time the "outsider" section, comprising in large numbers the poorly qualified, often minorities and immigrants, swelled the ranks of the precariat.

"Not in Education, Employment, or Training" (NEET) is a way of characterizing a subsection of young people likely to enter the precariat. In the UK, the Great Recession brought a rise of young people experiencing such exclusion from the labor market either after leaving education at age 16, the end of compulsory schooling - but also after the completion of some further education (Schoon and Lyons-Amos 2016, 2017). There are, however, distinct cross-national differences in identifying NEET. Reflecting the relatively compressed transition to work in the UK compared with other countries, the age limits for NEET were set originally there at 16-19. In contrast the OECD (Organisation for Economic Co-operation and Development), in company with the European Union (EU), set the boundaries as $18-25$, reflecting a continuing period of postponed independence.

NEET status may in some instances be a voluntary lifestyle choice, especially among those who could continue education or vocational preparation but choose not to. In most classifications, NEET also confusingly includes young mothers, apparently denying that caring for small children can be an occupation in its own right. Most frequently, however, NEET signals the manifestation of a "trajectory of disadvantage" (Bynner and Parsons 2002, 2007; Schoon \& Lyons-Amos, 2016) to which the Great Recession added reinforcement. Moreover, precariat status has spread increasingly from this mainly traditional working class unskilled segment of the work force where it began (Standing 2011), and can now be found across the educational achievement spectrum to the middle reaches of the skilled manual and nonmanual sectors and even the graduate sector. Hence the Great Recession had a significant role in contributing to the growth of the precariat.

Processes of standardization, individualization, globalization, stratification, and precaritization are not mutually exclusive, and can unfold in the same or opposite directions - as argued by Iacovou, Crosnoe and Smith, Lyons-Amos and Schoon, Wightman et al., Blossfeld, and GrohSamberg and Wise. For example, Crosnoe and Smith (Chapter 6) suggest, that the nature and direction of recession effects might not be as clear-cut as assumed, with variations in the degree to which economic downturns incentivize educational investments (or not). According to the "income effect" argument short-term needs are assumed to trump long-term investments, especially among the more disadvantaged, leading to truncated rates of educational attainment in hard times as young people focus on the labor market to meet families' immediate needs. 
Conversely, the "substitution effect" contends that hard times decrease the opportunity costs of education in the short term (i.e., less money to be made means less opportunity to forego). Consequently, educational enrollment should increase as jobs are scarcer and lower paying. The findings presented by Crosnoe and Smith (Chapter 6), and Lyons-Amos and Schoon (Chapter 12) supply evidence supporting both effects (income versus substitution), depending on social location, with a greater tendency toward substitution effects among the best educated and income effects more common among the disadvantaged.

\section{Individual and Collective Adaptation}

We now move to consider how structural forces impact on processes at the micro-level, and describe how individuals adapt to and assume control over their environment. Individual and collective adaptation can motivate various manifestations of adaptive (or maladaptive) identity development, comprising processes of individual agency and engagement as well as family socialization. The experience of economic hardship, joblessness, or underemployment can undermine constructive adaptations, i.e., positive outlooks and behaviors, as people lose confidence in the government and in other state institutions. The research suggests that the period of early young adulthood (between the ages of 18 and 25) seems to have become a particularly sensitive age range, while exposure to a recession before age 18 or after 25 has had less impact on beliefs about life chances and capabilities (Giuliano and Spilimbergo 2014).

However, there is also evidence to suggest that in situations where external forces are not overwhelming, and given some level of support and resources, maintaining high aspirations, certainty about career goals, and active job search, can help to protect relatively disadvantaged youth from the brunt of economic downturns. That is to say, young people who sustain high levels of agency and are proactive in seeking solutions to their difficulties are more likely to avoid becoming NEET than their less ambitious peers (Duckworth and Schoon 2012; Mortimer et al. 2014; Schoon 2014; Vuolo, Staff, and Mortimer 2012), although there can also be the risk of being overconfident (Schoon and Lyons-Amos 2017), or "blaming the victims" in case it is not possible to reach desirable goals. It is thus important to consider the role of individual resources and capabilities as well as support from the family or from the wider social context when examining the impact of the Great Recession. This reflects the key life course principle of "linked lives."

Young people have from the early teens a number of venues for establishing and maintaining social relations, including at home, at school, 
at work, and increasingly through the peer group. But in relation to occupational destinations the family is likely to be the key source of communication, support, and advice (Banks et al. 1992). For example, as shown by Wightman and colleagues in Chapter 10, the Great Recession effects are evident in young people relying for much longer on financial support from parents.

\section{Linked Lives and Family Socialization}

The effects of economic pressures on developmental processes are not uniform across outcomes and there are distinct mechanisms linking experiences of economic hardship to processes within the family as well as perceptions of available opportunities and constraints. These processes in turn help shape individual and collective behaviors and agency.

Families and other primary environments, such as work settings and schools, are important socializing contexts for individuals leading interdependent lives. Change in these environments tends to occur across cohorts. Consider, for example, the difference between growing up in the hardship years of the Great Depression and in a society mobilized for global war in 1940-1945. These historical times represent two worlds of adolescence and young adulthood defined by the contrasting experience of family members, friends, and neighbors. To understand this social change in the linked lives of young people, research has focused on evolving social networks over time.

Elder (1974/1999) assumed in Children of the Great Depression that a major loss of income would be "perceived as such by family members" and put families under profound stress. The original study did not have the data to put assumptions of the by now well-known "family stress model" to the test. However, a subsequent US study of rural farm youth and their families in Iowa during the agricultural recession of the 1980s was able to do so by relating family socioeconomic disadvantage to perceptions of economic pressure (Elder and Conger 2000). As expected, family hardship was highly predictive of the level of economic pressure reported by the Iowa parents, which in turn accounted for their depressed feelings and strained relationships, which in turn affected the effectiveness of their parenting and the well-being and adjustment of their children.

Walper and Friedrich (Chapter 11) build upon these US studies by investigating how adolescents perceived the economic pressure experienced in their family and its impact on their relations with their parents, using the German Family Panel Study (Pairfam). Although the Great Recession was less severe in Germany, compared to the USA and the UK, the economic 
pressure experienced by the German adolescents diminished their sense of closeness to parents and increased their conflict with them. In turn, this adverse change in family relations reduced their sense of well-being and family satisfaction. Relationships with fathers were especially critical for this post-high school adolescent sample, who in the face of parental unemployment, saw the male breadwinner status as a role model and major means of family support increasingly challenged. This finding is echoed by Mortimer, Kirkpatrick Johnson and Mont'Alvao (Chapter 13), who show that when economic conditions deteriorate, they can threaten parents' capacity to act as successful role models, which in turn is associated with impaired agency among their offspring. Together these findings may be seen as replicating, in a quite different economic context, many features of Elder's (1974) Great Depression study.

Although the short-term effects may be modest, they may be followed by more serious outcomes - regarding experiences in the labor market of unemployment, or even impaired health. Moreover, the Great Recession effect may launch a growing emotional gap between the generations. The timing of economic pressures can be an enduring source of intergenerational conflict when it occurs during the formative years of early adolescence. For example, it may have a negative impact on a young girl's plans for more education, a job, or marriage, and as shown by Lyons-Amos and Schoon (Chapter 12), affect decisions about making the step into parenthood. In the direct aftermath of the recession, couples delayed the start of their families - especially those with the least resources.

The principle of linked lives extends well beyond the boundaries of a nuclear family and household to relatives and friends. These significant others may be an important source of social support and conflict in an economic crisis or a source of greater economic burden. The Children of the Great Depression study did not have the data to bring this community of significant others into consideration, although they were occasionally mentioned. However, the Iowa study of rural families in an agricultural recession included interviews and surveys of the children's grandparents. Grandparents often filled the support gap in families torn by conflict and emotional tensions. The residential proximity of rural farm families and kin made supportive figures very real in the lives of their grandchildren who lived in disadvantaged family circumstances through the later years of adolescence. Similarly, in Walper and Fiedrich's Pairfam study (Chapter 11), economic pressures extended beyond the nuclear family, to reconstituted families, reducing closeness and increasing conflict especially with stepfathers.

Longitudinal studies, including Children of the Great Depression, have followed young people in hard times across the transition to young 
adulthood, but none have collected and analyzed financial data from parents that would enable us to understand how young people support themselves after high school education. Chapter 10 by Wightman and colleagues documents, based on analysis of data collected for the US Panel Study of Income Dynamics, the impact of the Great Recession on parental financial support on both post-adolescents aged 18-23 and young adults aged $24-29$ years. Their study highlights the generalization that parental financial support tended to follow the demographic shifts of young adulthood, i.e., more support for offspring who were still in education than for those who were working or were married. The study also documents the upswing of post-adolescent education. Parent financial support may have influenced this trend and/or represented a consequence of it. Both causal directions seem likely, and further studies are needed, with the concept of linked lives being clearly relevant to understanding both of them.

\section{Individual Agency: Self-Efficacy and Motivation to Succeed}

How did the Great Recession impact on individual motivation and selfefficacy and vice versa? The development of individual agency nurtured within the family may be constricted by economic pressures to which the family is subjected, yet depending on available resources, it could also enable young people to withstand or overcome their disadvantaging situation or be the means of moderating its effects. Using data from the three-generation Youth Development Study, Mortimer, Kirkpatrick Johnson and Mont'Alvao (Chapter 13) show how economic turbulence can undermine achievement orientation through socialization processes within the family, at school, and in the workplace, focusing on processes of social learning and learning-generalization. It follows from the individualization hypothesis that since the 1970s individual behavior has become less bound by traditional norms and values and sources of collective identity such as class and gender. However, as we have seen, there is consistent evidence emphasizing the persistence of structural pressures and social advantages and disadvantages, underlying the opportunities and obstacles to life course construction that today's young people face.

For example, Mortimer and colleagues highlight the differential vulnerability of families and children based on parental education, parental history of unemployment, and parents' own achievement-related attitudes. Yet, although structural constraints, such as the experience of economic shocks, can undermine intrinsic motivation and work values, young people reacted to their parents' economic hardship in different ways, depending on the family's history of achievement. As the level of 
parental economic strain increased, children lowered their aspirations for the future, especially those children with less educated parents. Those with college-educated parents, however, maintained their aspirations even in the face of economic hardship.

Another moderator was the experience of parental unemployment. As parental financial hardship increased, children's achievement motivation decreased especially when parents experienced periods of unemployment. Children whose parents had no experience of unemployment during the prior decade tended to maintain their educational aspirations and motivation. The findings highlight processes of cumulative risk, as well as potential compensatory processes and specific sensitizing experiences. Another interesting finding by Mortimer and colleagues, already mentioned earlier, is that when economic conditions deteriorate, they can threaten parents' capacity to act as successful role models, which in turn undermines their offspring's sense of agency.

Examining young people's perception of the future in the aftermath of the Great Recession, Leccardi (Chapter 14), draws on evidence from a cross-national survey and case study data, to show that uncertainty and short-termism characterize young people's outlook. Across Europe young people are fairly pessimistic about the quality of their future lives. Yet instead of fatalism and resignation they appear to be engaged in creating a new and positive relationship with the future, interpreting uncertainty as a window for new possibilities and the unexpected, a potentially risky but positive experience. The way uncertainty is interpreted is shaped by available economic, social, and cultural resources, and varies across countries.

For example, young people in Scandinavian countries (and the USA) were more optimistic about the future than their peers in southern Europe, partly due to the protection provided to young people through welfare policies - or in the case of the USA, a considerable confidence in meritocratic principles. For some, the notion of uncertainty was associated with the possibility for new options and self-exploration - the anticipation of change, and avoidance of everything that appears to be permanent or taken for granted. They can be understood as the "trendsetters" of their generation. Others continued to aspire to entirely "normal lives" involving getting married, having children, a house, a job, and a pension, yet they also conceptualized their future in terms of mobility - involving geographical (living in different countries) or existential change and a lack of opportunity to plan ahead. Differences between countries were greater than those between age groups, pointing to shared beliefs across the generations, and collective adaptation depending on perceived opportunities. For example, young adults in Germany tended to perceive their personal 
future more positively than their country's future, as a recent survey in Germany (Hurrelmann and Traxler 2016) indicates. Their outlook seems to reflect dissatisfaction with the state of their nation and trust in their own capacity to shape their future biography instead.

The findings suggest that even in situations of grave economic hardship young people strive to maintain efforts to exert control over their lives. They are not passively exposed to external events and perceive they can be in charge of their own destiny, which in the USA would be characterized as the so-called American Dream. This is the assumption that a better life is possible and that individual efforts and capabilities will be rewarded. There is, however, growing concern that the American Dream is evaporating (Putnam 2015; Schoon and Mortimer, 2017) and that it is becoming increasingly more difficult for young people to achieve their ambitions of moving up the social ladder, or even to maintain their status.

\section{Political Values and Engagement}

Political engagement is another manifestation of agency, this time referring to active citizenship; that is to say interest in and interaction through voting with the democratic structures, processes, and decisions of government locally and nationally. Such activity is typically framed by the alternative ideologies, parties, and programs on which the regime's mandate is based. In the broader sense, political engagement attaches to the issues of the day to which government policies are directed and around which demonstrations and movements of protest and advocacy may be formed often en route to becoming political parties. In accordance with the "resource model" of political activism, educational achievement is a strong predictor of such activism (Bynner and Ashford 1994). But the concern here is mainly with two kinds of engagement: political satisfaction as expressed in believing and trusting in government and when eligible, exercising the right to vote. Was such engagement and the values underpinning it weakened or strengthened by the Great Recession?

Janmaat (Chapter 15) examines the impact of the Great Recession on young people's political attitudes and civic values across Europe. He focuses on three categories from Pippa Morris's (2011) framework for conceptualizing political satisfaction, comprising satisfaction with "regime institutions," "regime performance," and "regime principles." He provides a trend analysis using data collected for the European Social Survey (ESS) and Eurobarometer across a ten-year period starting in 2002, as well as longer-term data from the World Values Survey (WVS) from 1981 to 2010-2013. Perceptions of political satisfaction among young people born after 1974 are compared with those of older cohorts. 
The findings suggest that young people's support for political institutions such as parliament has been declining since 1981, and that it is lowest in countries with relatively high levels of youth unemployment. His findings further suggest that the economic performance of a country matters with respect to attitudes, rather than a country's welfare regime or general levels of prosperity. Young people in economically low performing countries showed dramatic declines in political trust and voting levels, and a sharp increase in participating in demonstrations. Against this background of attitude change, young people's support for universal values identified with democracy as a system of government, however, appears to be less affected and relatively immune to socioeconomic shocks, such as the Great Recession, although levels of support for democracy are lowest among younger age groups. The findings appear to support the assumption that values are relatively stable and unaffected by economic events, while attitudes toward institutions are less stable and more directly relate to the economic downturn (Schwartz 1994). It is thus a matter of concern that support for democracy appears to be on a downward trend for younger age cohorts.

Janmaat's analysis shows that it is politicians and the "political establishment" (institutions and performance) to which young people are hostile and to which they attribute the labor market recession problems that they face. The downward trend in support for the principles of democratic government among younger age cohorts points to a more general malaise that might be more difficult to heal. It is in such situations that "new broom" movements from the left as well as from the right - often with charismatic leaders - have been growing in appeal, as evidenced across the neoliberal industrialized world, with particular prominence in the USA (see also Bartels 2013), as well as the UK and Germany.

\section{Health and Well-being}

Physical health is not a major issue for most young people. The ravages of late adult life are a long way off for them - hence the focus here is on risky behaviors, which characterize the youth stage of the life course. Smoking, drinking, experimenting with drugs and overeating are a common experience, some of which can turn into serious problems ranging from addiction to obesity. In the identity exploration involved these longer-term harmful effects are not a sufficient inhibitor to avoid doing them - especially when peer group pressures are strong. Sexual activity both via casual and later more stable relationships is also likely to be a feature of social life for many, with consequent health risks. Addiction to computer games (mainly young men) and social media are other 
potential risk factors. A common feature of the social world that young people inhabit can be various forms of stress to which we might expect events like the Great Recession to contribute. Hence we might expect psychological rather than physical well-being to be put under threat and that the effects are likely to be age-driven, reflecting the stage of life the young person has reached.

The findings confirm the dependency of health effects on the timing of events, i.e., there are differences by age, as well as variations by outcome. That is to say, it is important to know when the event occurs in the life of a developing individual, and to differentiate between multiple indicators of health outcomes while recognizing that the prevalence of physical health problems in children below the age of 16 is generally low. For example, the health of young teenagers (aged 11-15 years) appeared to be less affected by the Great Recession than that of young adults (aged 20-25 years). As shown by Pförtner and colleagues (Chapter 16), the self-reported psychological health of children aged 11 to 15 years in the Health Behaviour in School-Aged Children study seemed not to be significantly affected by the economic downturn (assessed by unemployment rates within countries). In Chapter 17 Cavanagh focused on health outcomes among an older group, 20 to 25 -year-olds, using data from the US Panel Study of Income Dynamics (PSID) and Transition to Adulthood Supplement. She found that self-assessed general health declined in the immediate aftermath of the Great Recession. However, health behaviors of young adults (smoking, drinking, and obesity) did not appear to have been affected.

Apart from timing, we also have to consider the role of structural factors in health. For example, the study by Pförtner and colleagues (Chapter 16) shows that across all countries children from less affluent homes reported higher rates of psychological health problems than their more privileged peers. However, across different countries family affluence did not modify the relation between recession indicators and psychological health symptoms, i.e., on average the Great Recession did not show a stronger effect regarding the health of adolescents from less privileged families. Focusing on young adults instead of adolescents, however, Cavanagh identified parental education as an important buffering factor. Health differences were largest among those raised in less educated families, and young people growing up with less educated parents reported lower levels of general health in the immediate aftermath of the Great Recession.

In summary, the findings relating to individual and collective adaptation highlight that interactions between individuals and socioeconomic context have to be understood within a life course developmental 
framework, where patterns of experience can change over time. Not all young people responded to the recession in the same way. For some, especially those with the least resources, the impact of the recession had been devastating, undermining previously available pathways and opportunities, as well as their motivation and outlook to the future. Yet, we also find evidence of positive adaptation in the face of adversity, demonstrating human capacity to adjust to potentially harmful situations, to maintain effective functioning or to develop new orientations. Variations in response depend on availability of accessible resources within the family context and wider community, and most importantly, institutional initiatives to moderate the effects of the economic downturn.

\section{Institutions and Policies}

We turn now to a theme that has emerged throughout the preceding sections: the role of institutions for managing the transition from school to work and in ameliorating the labor market effects of such economic shocks as the Great Recession. As argued by Ashton, Mont'Alvao, Mortimer and Kirkpatrick Johnson, Green and Pensiero, and GrohSamberg and Wise, national policies, educational institutions, and labor market regulations made a big difference in the way the Great Recession affected youth transitions. In response to the changing and more individualized opportunity structures, college and university enrollment has increased, based on the expectation of young people, which is shared by their parents, teachers, and counselors, that a college degree is the prerequisite for a career or at least for securing employment. Public opinion, business, and governments also subscribe to the belief that a higher education certificate or degree will protect against precarious life course transitions (Putnam 2015). There are, however, as Ashton (Chapter 2) documents, variations across countries in how the transition from education to employment is organized. Because of Germany's highly institutionalized approach to the management of youth transitions, we use it to benchmark against other less coherent systems, such as those in the USA and the UK.

\section{Transition Systems}

In the USA the transition pathways are largely defined by an education system with a substantial segment of private providers, a flexible labor market, and failed national programs for improving vocational and technical training. In accordance with the individualization hypothesis individuals are perceived to be responsible for their career decisions, having to 
accumulate the necessary resources for managing life course transitions. The young people who do not succeed in their transition to the labor market tend to be regarded as low achievers and lacking initiative. This belief contributes to "blaming the victims," neglecting the economic and political causes of a failing transition system for the most vulnerable, concentrated for example, in the US case among African American and Hispanic youth, a disproportionate number of whom, compared with other OECD countries, are incarcerated (Carson 2014).

Generally, the state tends to provide the framework of equal opportunity and does not compensate for individual resource deficits. Moreover, rather than boost state institutions to help young people withstand the recession's damaging effects on the transition process, the response was reduced state funding for them and increased tuition fees mitigated by federal support for low-income students (loans and grants). As highlighted in a Special Issue published in the Annals of the American Academy for Political and Social Science, the focus was on relieving, in the adult population, severe poverty, hunger, and on providing shelter and income support through tax measures (Danzinger 2013). In consequence, more high school graduates opted for the less expensive community colleges, which offer shorter, mostly two-year degree programs and better connections with the local/regional employers than the four-year degree programs of universities. For low-income high school graduates the decision to take this pathway can be seen as a realistic reaction to the longterm trend of a vanishing youth labor market which, as Staff, Ramirez, and Cundiff (Chapter 7) point out, used to be a way of gaining work experience, to acquire social skills, and build connections with potential employers. The jobs that used to be available to teenagers increasingly became the only means of employment for young adults whose needs gave priority access to them. As the contributions by Crosnoe and Smith (Chapter 6) and Mont'Avalo, Mortimer and Kirkpatrick Johnson (Chapter 3) suggest, the Great Recession did not dramatically change this situation, but at the same time the high school curriculum became more demanding and more young people entered the post-high school academic route.

The UK, in turn, is characterized by a centralized education system, a deregulated labor market with a large segment of low-skilled and nonstandard jobs, and checkered attempts to establish a vocational training system. The long standing tradition of five-year apprenticeships in mostly male-dominated occupations, such as the various branches of engineering, was dismissed as "time serving" by the Thatcher Government of the 1980s. Such apprenticeships were replaced first by "Youth Training Schemes (YTS)" and then by a system comprising 
a one-year (foundation) and a three-year (advanced) "New Modern Apprenticeship" program directed at all school leavers with accreditation at different levels by a new system of National Vocational Qualifications (NVQs). More recently, maybe as a response to the Great Recession and/or the increased compulsory school leaving age (which was raised from age 16 to 17 in 2013 and to 18 in 2015), government policy has been directed at building up the apprenticeship system and vocational training. Currently the apprenticeship system attracts well below onefifth of the age cohort aged 18 or younger, while half of the new apprentices are in fact in their early twenties. However, the poor quality of much of the work-based training available to teenagers, and low credibility of the certification arising from it, has yet to convince employers and families that apprenticeship is a high value alternative to staying on in education. For young people not planning to go to university, the Further Education (FE) colleges provide the main post-compulsory education route for gaining vocational qualifications or making good on previous poor school performance. But more generally, as in the USA, young people and parents do not regard a vocational training pathway as a promising option, nor it seems does the government. As in the USA, there were cuts in public funding of the Further Education colleges and major increases of university tuition fees.

In Germany the diverse education and training institutions are a component of a social market economy that includes free education. Governance is achieved through a "social partnership" comprising local government, employers' organizations, and trade unions in maintaining and reforming the apprenticeship pathway, with a direct link to the employment system. The system resides in a strongly established "training culture" targeted at supplying an occupational identity to trainees and providing the basis of employability and citizenship in the German states. There are five major pathways: (1) Vocational Education and Training (VET) i.e., apprenticeship under a training contract or fulltime vocational school; (2) the preparatory VET ("transition system"); (3) Dual Studies (combining VET and college); (4) university of applied sciences; and (5) research university. Enrollment to Dual Studies and universities has been growing in the past decade, as a response to the employment uncertainty created by the Great Recession.

Germany has been building its Dual System of apprenticeship for more than a century and has maintained its institutional set-up across changes of government. Although the system is still popular, there are a growing number of upper level school graduates who opt for university studies and the upper occupational segments of the labor market. The attractiveness ofVET in the crafts and manufacturing is declining and there is 
a move toward high-end apprenticeships in business and IT. Moreover, as Blossfeld (Chapter 9) shows, based on NEPS (National Economic Panel Study) data, the Great Recession prolonged the duration of young people's job search in Germany: before the Great Recession 40 percent found a job within two months, afterward only 25 percent did so.

\section{Pathways and Policies}

During and after the Great Recession, the respective upper secondary education and training pathways in Europe and North America generally continue to differentiate the course and outcomes of youth transitions. Green and Pensiero (Chapter 4) show with time series based on OECD data that the link between educational credentials and labor market conditions still structures young people's transitions. The education-employment gap has become wider in the English-speaking countries than in Germany. Graduates are confronted with a longer duration of job search, and many end up in short-term employment contracts. The institutional arrangements for managing higher education and employment pathways also differ in several aspects. German universities do not charge or charge only minimal tuition fees, while the UK and the USA do demand them and at ever increasing rates. The lack of a single set of institutional transition arrangements for the "non-college bound youth" in the USA and the UK also contrasts with the Germany's commitment to providing not only free further education, but also support for students of low-income parents by means of federal loans and educational maintenance grants.

Has Germany been an exception in coping with the impact of the Great Recession? The reunification of West and East Germany in 1990 brought with it increasing unemployment that caused the German government to develop a proactive labor market policy favoring deregulation, though within a framework of "flexicurity," i.e., flexible employment cushioned by a social welfare system. Employment, education, and social protection reforms initiated by the Labor (SPD) and Green Party coalition at the beginning of the twenty-first century restructured the distribution of school graduates in the transition process. The academic routes (postsecondary education) became more popular, because a degree is required for entry to the upper segments of the labor market, while the number of applicants for an apprenticeship was declining steadily, dropping by almost one-fifth since 2007.

Before and after the Great Recession there was an increase in less well-paid jobs and fixed term contracts, in the shadow of an intense political struggle over introducing a minimum wage (finally established in 2015). Findings based on the SOEP data, analyzed by Groh-Samberg 
and Wise (Chapter 8) comparing three age groups, suggest that the Great Recession slowed down employment entry and led to an increase of insecure employment. In particular, the younger age groups experienced more insecure transitions and were confronted with increasingly precarious job conditions. However, in contrast to the USA and the UK, the number of unemployed and inactive young people (NEET) declined as a result of the job centers' requirement that they accept low-income jobs or lose social benefits. Hence the German system's reduced levels of unemployment were achieved at the price of increasing inequality and insecurity.

Here a contradiction becomes evident in Germany's life course policy. On the one hand, its institutional arrangements protect and stabilize young people's transitions to adulthood; on the other, the available pathways are a source of stratification signaling an implicit reproduction of social inequality. VET and higher education routes are segmented by the entry level required. Lower level school graduates (Hauptschule), often comprising immigrants and refugees, are referred to apprenticeships in the lowest segment of the occupational structure or must enter the fallback "transition system" as a substitute. Intermediate level occupations are accessed after completing the Mittel- or Realschule. Access to university is mainly restricted to upper level secondary school (Gymnasium) graduates. In Germany's three-tier school system the allocation into academic and vocational routes still occurs quite early in the young person's educational career, from around age 10.

What route is taken depends to a large extent on prior academic attainment as well as the parents' level of education, supplemented by teacher advice, and contributes to the stratification of life chances. Thus, early educational advantages and disadvantages accumulate toward unequal employment outcomes and the division of "insiders" and "outsiders" in the labor market - the incipient precariat. Because of the persistence of social inequality in access to the stratified system of education and a low level of permeability between school tracks, life chances are still transferred across generations. Despite its segmentation, the institutional fabric reduced the risk of being NEET and kept youth unemployment at a low level - but at the price of persisting inequality.

Moreover, the low rate of Germany's youth unemployment reflects the country having the lowest birth rate in Europe. The proportion of under-20-year-olds declined from 30 percent in 1970 to 18 percent in 2015; thus the size of the school leaver cohort has been getting smaller. The number of young people leaving school early dropped by one-fifth, whereas the number of college-bound students increased by 30 percent between 2007 and 2012. The lower level school (Hauptschule) has lost 
almost half of its pupils and its teachers have become accustomed to handling social and ethnic heterogeneity, and have assumed the role of mentors and benevolent gatekeepers.

The challenges for life course policy in Germany for the coming years are the integration of refugees, worsening social inequality, a polarizing labor market, and creating a better linkage of the Dual System to higher education pathways. For the UK the dominant issue is the relationship with the European Union (EU) (post the decision to leave the EU, or "Brexit") and its potential impact on the labor market and young people's outlook on life. In the USA issues of engagement rather than isolationism (reintroduced following the presidential election of Donald Trump) and the strengthening of welfare reforms to counter social exclusion are crucial. Apart from the effects of migration and future economic upheavals in all countries the major concern must be how to construct a viable VET system of education and training pathways that both matches the needs of the contemporary labor market while having validity in the eyes of its potential users.

\section{Conclusions}

This chapter has drawn together evidence suggesting that following a period of relative economic stability the effects of the Great Recession on youth transitions varied substantially between the UK, the USA, and Germany. The institutional mechanisms that young people can use to improve their starting position in the competition for good jobs and a successful life course transition to independent adulthood have been stabilized in Germany, promoted by the government's "life course policy." However, as in the USA and the UK, successful labor market integration for young adults is limited by market forces, a stratified education system, and lack of parental material and social resources, especially among immigrants.

As Wightman and colleagues (Chapter 10) emphasize, the reasons for the delayed transition and the scope of action arising from it must be specified according to the families' socioeconomic circumstances, young people's educational achievements, their occupational goals - and the extent to which welfare arrangements are available for stabilizing passages and to enable recovery from failures. The Great Recession placed many families and children under profound stress, involving income loss, economic insecurity and increases in poverty, requiring the continued examination of how economic forces impact on families, and consideration of how to strengthen families in providing prolonged support for their children. In Germany, the UK and in the USA the Great Recession 
triggered processes of cumulative disadvantage especially for the cohorts with little education and the narrow skill profiles that led to precarious pathways between education and employment during and after the financial crisis.

To map accurately the interplay between economic forces and families, the ways in which they impact the transition pathways of current cohorts and associated long-term consequences, we need however a longer window of observation. Although the Great Recession officially ended in 2009 , the effects of the downturn can be expected to continue for several years to come. Moreover, further analysis should also include comparison with countries in southern Europe that were dramatically affected by the global financial and Euro crises. The economies of Greece, Spain, and Italy could not recover and had frightening youth unemployment rates above 40 percent at the beginning of 2016. Moreover, the economic and political situation in Southern/Latin America (Brazil and Mexico) has become worse. Brazil struggles with its worst recession since the Great Depression of the 1930s, resulting from falling world market prices for oil and mineral resources and corruption in government. "Corporatist" countries such as Germany, Austria, Switzerland, and the Nordic and Benelux countries had a better crisis management than most others based on a stable system of inclusion. However, labor market entrants in the wake of the Great Recession are offered mostly temporary contracts that may be stepping stones to a career if they offer work experience and decent wages, but a downward path of exclusion if they do not. Future research needs to monitor the long-term consequences of these changes. It is important to assess the likelihood of progressing from the temporary jobs available to permanent employment: which economic sectors and skill levels facilitate careers and support social mobility for young men and young women, and for those with different migration backgrounds?

The consequences of the 2007/2008 banking crisis hit young people in all three countries examined here, forcing them to come to terms with insecure and low-income employment and insurmountable housing costs. Hard times affected the income situation of households leading many lower socioeconomic status (SES) young people, especially immigrants, to look for early employment opportunities, thus speeding up the transition to adulthood. On the other hand, as Crosnoe and Smith (Chapter 6) also show, enrolling in higher education can be viewed as a substitute for lack of employment opportunities among the middle class. Participation in education increased in all three societies, while full-time employment declined. In the absence of institutional help, support provided by the family becomes more important. Yet, there is no legislation or generally accepted legal framework regarding the timeframe for parental 
responsibility (Jones 2009). As shown by Wightman et al. (Chapter 10) intergenerational solidarity increased in the USA with the trend toward postsecondary education enrollment - which requires paying tuition fees. At a time of reduced public support, when financial assistance was decreasing, family support was seen as the vital means of economic survival and coping with ever escalating inflation of prices, especially in the housing market. Yet, a considerable number of young people will not have access to viable family based financial and emotional support.

\section{What Can Comparative Youth Transition Research Accomplish?}

An analysis of the different voices and political narratives - national governments, European Commission, international organizations (UN, OECD, ILO), the media, public opinion, and young people themselves (Occupy Wall Street, Arab Spring, student protests against tuition fee increases) - can test the accuracy of portraying the younger generation. Especially, the superficial labels for "generations" invented over and over again by the media must be corrected for not taking into account the national, economic, and subcultural diversity of young people's living circumstances and life chances. The long-term impact of the Great Recession calls for social scientists to suggest political reforms of labor market and social security arrangements that focus on the most vulnerable in society, in particular hard-hit families and youth who do not have the social, material, and personal resources for coping with unemployment and who face uncertain prospects.

Studying the extent to which transforming social and economic contexts are causing more stratification of youth populations will bring a better understanding of whether there will be more disparity in educational outcomes than before - more dropouts, more graduates with nonstandard jobs, and large debts. The changing landscape of the transition process, however, also calls for a better understanding of human agency processes, of how young people engage in decisions and decide whether to make investments in education with uncertain returns. This also implies the analysis of parent-child - and person-context interactions, taking into account the range of options available for school leavers in general, for lower SES young people and those with a migration background, and examining the ways in which they cope with the structural changes with which they are confronted.

In addition to quantitative analysis of national data sets, case studies would also be useful for taking a closer look at the reasons for and patterns of staying on in education or employment or dropping out. In the USA, the $\mathrm{UK}$, and Germany there is a substantial continuing proportion of young 
people who fail to obtain a qualification at all because they leave education early, often taking up unskilled temporary work instead. Dropping out from the education and training system may be a step toward adulthood signaling dissatisfaction with the world of schooling and resistance. Within this context it is important to understand the individual reasons and perceived "push-and-pull" factors. Most important, from the perspective of life course policy we have to ask if there is flexible and effective management available for reentering or switching pathways. Support for young people is needed to overcome, as an alternative, the lure of early, often dead-end, employment in low wage jobs. Case studies could also illuminate how the situation of being NEET, the precariat in the making, is perceived. Is the experience of NEET considered as a time of hanging around, of floundering, or as a moratorium period for developing identity through the exploration of opportunities? And what in demographic and educational terms distinguishes the groups with these different orientations?

Moreover, we need a better understanding of the processes underlying civic disengagement and declining support for democracy and the role that education might have in reversing these. Has the time come that young people no longer support the democratic process of negotiation and integration and rather look for a strong leader? Are they putting the blame for reduced public services in the aftermath of the recession and painful austerity measures on immigrants and other "outsiders"? If the Great Recession turns out to have accelerated trends toward a decline in democratic values, it will significantly impact on European and also US politics for a long time to come.

The analysis of the consequences of the Great Recession is at its best when it succeeds in highlighting the interactions between markets, institutions, population change, family interactions, and individual decisionmaking in a life course framework. What contribution did deregulation of financial services make to the international banking debacle and its recession consequences for young people? How appropriately have labor market standards been modified and education and training pathways adapted to the needs of the IT-driven knowledge economy? How is it that postsecondary education and VET is ceasing, on UK and US lines, to be regarded as a public good and is becoming to be seen as a private resource to be paid for? What information and guidance do young people need to make an informed choice regarding the timing and sequencing of life course transitions and optimum selection between different occupational pathways? What educational intervention is needed to reengage them in the democratic process? How does the prolonged dependence on parents influence interactions and relations between the generations?

The influence of market forces and institutionalized sorting mechanisms for determining life course pathways calls for linking the political 
economy of youth transitions with the analysis of young people's perceptions of opportunities, their plans for the future, and their interactions with significant others. As shown by the contributions to this book, youth prospects do not depend primarily on individualized pathway decisions, but on family support and the employment contexts that are changing at an accelerating pace through ever-advancing technological change, from the birth of IT to the farthest reaches of robotics.

Looking back, the Great Recession did not bring about a radical transformation of transition systems; the financial crisis was not an instance of a "creative destruction" as Joseph Schumpeter (1942/1975) would call it. Secular economic trends in education and labor markets were not basically changed, but rather they were speeded up a little. At the individual level the Great Recession was associated with stunted achievement orientation and inhibited learning motivation, especially among the most disadvantaged. Young people's health and well-being were however not much affected. Basic beliefs in democracy and the value of education were not fundamentally undermined, yet there was a decrease of confidence in government and institutions and growing levels of distrust, spilling over to destructive as well as constructive activism, the outcomes of which remain to be seen.

\section{Policy Postscript}

The greatest challenge of all arising from technological transformation and economic restructuring, reinforced by the Great Recession, is the scarring associated with failed pathways through the transition stages of postsecondary education, training and early employment, and the growth of a precariat stemming from it. The prospect of a sizeable marginalized and politically disengaged section of the population largely excluded from mainstream opportunities is a dystopian vision in complete denial of the democratic assumptions on which the idea of a fair and equal contemporary society was based.

The trend in the opposite direction of gross disparities in wealth, income, and life chances driven by the excesses of neoliberal capitalism emerges almost as if from social science fiction in such scenarios as the Great Recession. Its earlier version in the 1930s has parallels in terms of the different forms of hardship and social breakdown arising from a collapsed banking system. The difference is that this time the collapse was driven by the dominance of shareholder values and technological change at a phenomenal rate. Its counterpart was globalization managed by unregulated worldwide corporations and international banking spurred on by acquiescent governments, with in practice little accountability to 
anyone but themselves. If the foundation of blighted life chances for individuals in the modern economy is failed youth transitions, then the answer to them must be sought in the successful mechanisms of the past adapted now to meeting the new challenges of contemporary times. Against a relatively recent background of totalitarian politics and the rebuilding of a corporatist society on democratic lines, the German example is particularly illuminating. The answer is seen as lying in effective democratically accountable institutions in which all stakeholder sections of the corporate state - politicians, employers, and trade unions - not only supply the governance, but also have a sustained commitment to, and vision for, ensuring the next generation's successful entry into adulthood.

What of young people themselves? They are the stakeholders whose collective agency will be the means of ensuring a future that is both productive and fulfilling whatever the challenges of the occupational, social, and political worlds they enter. This is where their adult life course and that of their children will be constructed, and their engagement is the source of future change. They are the key to defining the institutional framework that is needed, while also the potential victims of failure to create it.

Progressive and dynamic institutions can both mediate and moderate pressures from the external economy, thus supplying the essential protection that the coming generations need in optimizing life chances and avoiding exclusion. At times when there is exceptional economic strain, the institutions concerned with managing the education and training system of any country become the key agents of social policy concerned with ensuring not only the immediate but also the long-term welfare of its citizenry - a prerequisite for social cohesion. This responsibility does not begin and end with the youth transition years but needs to apply throughout the life course to secure the social, occupational, and economic outcomes embodied in the capability that individual citizens, their families, and society need. Lifelong learning managed through Social Partnership is the means of building the political commitment to bring it about.

\section{References}

Arnett, J. J. 2000. Emerging adulthood: a theory of development from the late teens to the twenties. American Psychologist 55: 469-480.

Banks, M., I. Bates, G. Breakwell et al. 1992. Careers and Identities. Buckingham: Open University Press.

Bartels, L. M. 2013. Political effects of the Great Recession. Annals of the American Academy of Political and Social Science 650(1): 47-75.

Beck, U. 1992. Risk Society: Towards a New Modernity. London: SAGE. 
Buchmann, M. I., and I. Kriesi. 2011. Transition to adulthood in Europe. Annual Review of Sociology 37: 481-503.

Bynner, J. 2005. Rethinking the youth phase of the life course: the case of emerging adulthood. Fournal of Youth Studies 8: 367-384.

Bynner, J., and S. Ashford. 1994. Politics and participation: some antecedents of young people's political activity and disaffection. European fournal of Social Psychology 24: 223-226.

Bynner, J., and S. Parsons. 2002. Social exclusion and the transition from school to work: the case of young people not in education, employment or training NEET, fournal of Vocational Behaviour 60: 289-309.

2007. Illuminating Disadvantage: Profiling the Experiences of Adults with Entry Level Literacy or Numeracy over the Life Course. Research Report, NRDC, Institute of Education, London.

Carson, E. A. 2014. Prisoners in 2013. Revised in September 2014. Retrieved from www.bjs.gov/content/pub/pdf/p13.pdf (accessed March 27, 2017).

Côté, J., and J. Bynner, J. 2008. Exclusion from emerging adulthood: UK and Canadian perspectives on structure and agency in the transition to adulthood. Fournal of Youth Studies 11: 251-268.

Côté, J. E., and C. G. Levine. 2002. Identity Formation, Agency, and Culture. A Social Psychological Synthesis. Mahwah, NJ: Lawrence Erlbaum Associates.

Danzinger, S. 2013. Evaluating the effects of the recession. Annals of the American Academy of Political and Social Science 650: 6-24.

Duckworth, K., and I. Schoon. 2012. Beating the odds: exploring the aspects of social risk on young people's school-to-work transitions during recession in the UK. National Institute Economic Review 222 : 38-51.

Elder, G. H., Jr. 1974/1999. Children of the Great Depression: Social Change in Life Experience. Boulder, CO: Westview Press.

Elder, G. H., Jr., and R. D. Conger. 2000. Children of the Land: Adversity and Success in Rural America. Chicago, IL: University of Chicago Press.

Elder, G. H., Jr., and K. George. 2016. Age, cohorts and the life course. In Handbook of the Life Course, volume 2, eds. M. Shanahan, J. T. Mortimer, and M. K. Johnson, 59-85. London: Springer International Publishing.

Furlong, A., and F. Cartmel. 1997. Young People and Social Change. Buckingham: Open University Press.

Giuliano, P., and A. Spilimbergo. 2014. Growing up in a recession. Review of Economic Studies 81: 787-817.

Heinz, W. R. 2009. Structure and agency in transition research. Fournal of Education and Work. Special issue: Continuity and Change in 40 Years of School to Work Transitions 22: 391-404.

2002. Self-socialization and post-traditional society. In Advances in Life-Course Research: New Frontiers in Socialization, eds. R. A. J. Settersten and T. J. Owens, 41-64. New York: Elsevier.

Hurrelmann, K. and C. Traxler (Eds.). 2016. Fugend, Vorsage, Finanzen. Berlin: MetallRente.

Jones, G. 2009. Youth. Cambridge: Polity Press.

Jones. G., and C. Wallace. 1992. Youth, Family and Citizenship. Buckingham: Open University Press. 
Mortimer, J. T., F. L. Zhang, J. Hussemann, and C.- Y. Wu. 2014. Parental economic hardship and children's achievement orientations. Longitudinal and Life Course Studies 5: 105-128.

Morris, P. 2011. Democratic Deficit: Critical Citizens Revisited. Cambridge: Cambridge University Press.

Putnam, R. D. 2015. Our Kids: The American Dream in Crisis. New York: Simon and Schuster.

Roberts, K., S. C. Clark, and C. Wallace. 1994. Flexibility and individualisation. A comparison of transitions into employment in England and Germany. Sociology 28: 31-54.

Shanahan, M. J. 2000. Pathways to adulthood in changing societies: variability and mechanisms in life course perspective. Annual Review of Sociology 26: 667-692.

Schoon, I. 2014. Parental worklessness and the experience of NEET among their offspring. Evidence from the Longitudinal Study of Young People in England (LSYPE). Longitudinal and Life Course Studies 6: 129-150.

Schoon, I., and J. S. Eccles (Eds.). (2014). Gender Differences in Aspirations and Attainment. A Life Course Perspective. Cambridge: Cambridge University Press.

Schoon, I., and M. Lyons-Amos. 2016. Diverse pathways in becoming an adult: the role of structure, agency and context. Research in Social Stratification and Mobility, in press. Accessible at www.sciencedirect.com/science/article/ pii/S0276562416300178

2017. The social ecology of agency. Longitudinal and Life Course Studies, $8(1), 35-56$.

Schoon, I., \& Mortimer, J.T. (2017). Youth and the Great Recession - are values, achievement orientation and outlook to the future affected? International Fournal of Psychology, 52(1), 1-8.

Schoon, I., and K. R. Silbereisen (Eds.). 2009. Transitions from School to Work: Globalization, Individualisation, and Patterns of Diversity. New York: Cambridge University Press.

Schumpeter, J. A. 1942/1975. Capitalism, Socialism and Democracy. New York: Harper.

Schwartz, S. H. 1994. Are there universal aspects in the structure and contents of human values? Fournal of Social Issues 50: 19-45.

Standing, G. 2011. The Precariat: The New Dangerous Class. London: Bloomsbury.

Vuolo, M., J. Staff, and J. Mortimer. 2012. Weathering the Great Recession: psychological and behavioral trajectories in the transition from school to work. Developmental Psychology 48: 1759-1773. 
